\title{
Fitossociologia de plantas daninhas em monocultivo de milho e em consórcio com diferentes Fabaceae ${ }^{1}$
}

\author{
Anna Christina Sanazário de Oliveira², Fábio Cunha Coelho ${ }^{3}$, Jocarla Ambrosim Crevelari, \\ Ivana Fernandes da Silva 4 , Raquel Fialho Rubim ${ }^{2}$ \\ http://dx.doi.org/10.1590/0034-737X201461050007
}

\section{RESUMO}

O milho está entre os cereais mais cultivados e utilizados pela população mundial. Com o objetivo de efetuar o levantamento da comunidade de plantas daninhas no cultivo de milho em monocultivo e em consórcio, com diferentes Fabaceae, cultivado sob diferentes manejos, este trabalho foi realizado durante o período da primavera/verão de 2011/ 2012. Avaliaram-se os tratamentos: milho em monocultivo com adubação NPK na semeadura e com capina, milho em monocultivo sem adubação NPK na semeadura e com capina, milho em monocultivo com adubação NPK na semeadura sem capina, milho + mucu-preta, milho + crotalária e milho + feijão-de-porco. A capina aumenta o Índice de Valor de Importância (IVI) do falso massambará (Sorghum arundinaceum) no monocultivo, enquanto para o apaga-fogo (Alternanthera tenella colla) a adubação promove controle eficiente. O consórcio com a mucuna preta favorece o aumento do IVI do camalote (Rottboelia exaltata), já o consórcio com a crotalária favorece o falso massambará (Sorghum arundinaceum). As plantas de milho em monocultivo apresentaram maior altura (ALM) e peso de matéria seca (PMSM). Contudo, o monocultivo proporcionou plantas daninhas mais altas (ALPD), além de maiores no peso da matéria seca de plantas daninhas de folhas estreitas (PMSPDE). A capina no monocultivo elevou a ALM e o PMSM, apesar de elevar também a ALPD e o PMSPDE. O monocultivo com adubação com NPK na semeadura apresenta ALPD menor que o sem adubação completa; entretanto, o PMSPDE aumentou com a adubação. A adubação com NPK na semeadura no monocultivo eleva o PMSM. O consórcio do milho com a mucuna preta apresenta efeito semelhante sobre as variáveis analisadas em comparação aos outros consórcios avaliados, assim como os consórcios do milho com a crotalária e do milho com o feijão-de-porco apresentam efeitos semelhantes sobre as variáveis analisadas.

Palavras-chave: Zea mays, mucuna, crotalária, feijão-de-porco, plantio direto.

\section{ABSTRACT}

\section{Weed phytosociology in corn in monoculture and intercropped with different Fabacea}

Corn is among the most cultivated and used cereals worldwide. The objective of this study was to survey the weed community in corn cultivated in monoculture and intercropped with different Fabaceae in different management systems, during the spring/summer seasons in 2011/2012. The following treatments were evaluated: corn alone with NPK at sowing and weeding; corn alone without NPK at sowing and weeding; corn alone with NPK at sowing without weeding; corn with Mucuna aterrima; corn with Crotalaria juncea; corn with Canavalia ensiformis. Weeding increased the Importance Value Index (IVI) of Sorghum arundinaceum in monoculture, whereas fertilization

\footnotetext{
Recebido para publicação em 30/01/2013 e aprovado em 11/07/2013.

${ }^{1}$ Este trabalho é parte da tese de doutorado da primeira autora.

${ }^{2}$ Engenheira-Agrônoma, Mestre. Laboratório de Fitotecnia, Universidade Estadual do Norte Fluminense Darcy Ribeiro, Campus dos Goytacazes, Avenida Alberto Lamego, 2000, Parque Califórnia, 28013-602, Campos dos Goytacazes, Rio de Janeiro, Brasil. annaoliveira@uenf.br (autora para correspondência); raquel_rubim @yahoo.com.br ${ }^{3}$ Engenheiro-Agrônomo, Doutor. Laboratório de Fitotecnia, Universidade Estadual do Norte Fluminense Darcy Ribeiro, Campus dos Goytacazes, Avenida Alberto Lamego, 2000, Parque Califórnia, 28013-602, Campos dos Goytacazes, Rio de Janeiro, Brasil. fcoelho@uenf.br

${ }^{4}$ Engenheiras-Agrônomas. Laboratório de Fitotecnia, Universidade Estadual do Norte Fluminense Darcy Ribeiro, Campus dos Goytacazes, Avenida Alberto Lamego, 2000, Parque Califórnia, 28013-602, Campos dos Goytacazes, Rio de Janeiro, Brasil. jcrevelari@yahoo.com.br; ivanaf.silva@ @otmail.com
} 
promoted efficient control of Alternanthera tenella colla. The intercrop with velvet bean favored the increase of Rottboelia exaltata IVI, while the intercrop with Crotalaria juncea favored Sorghum arundinaceum. Corn plants in monoculture had the highest height (ALM) and dry weight (PMSM). However, the monoculture had the highest weed height (ALPD) and highest dry matter of narrow leaf weeds (PMSPDE). Weeding in monoculture increased ALM and PMSM, despite also increasing ALPD and PMSPDE. Monoculture with NPK fertilizer at sowing showed lower ALPD than the treatment without complete fertilization; however, PMSPDE increased with fertilization. The NPK fertilizer at sowing in monoculture increased PMSM. The intercrop of corn with Mucuna aterrima had similar effect on the variables analyzed in comparison with the other intercrop evaluated. The intercrops of corn with Crotalaria juncea and corn with Canavalia ensiformis also had similar effects on the variables analyzed.

Key words: Zea mays, Mucuna aterrima, Crotalaria juncea, Canavalia ensiformis, no-tillage.

\section{INTRODUÇÃO}

Na América Latina o milho é cultivado, principalmente, por pequenos produtores que necessitam de técnicas que, além de aumentar a produtividade, facilitam o manejo durante o cultivo. Entre as técnicas sustentáveis recomendadas para facilitar o manejo do milho está a utilização do consórcio com outras espécies.

O consórcio com o milho deve sempre ser realizado de forma adequada, pois assim, segundo Dan et al. (2012), evita a competição interespecífica entre o milho e as espécies que estão as outras consorciadas. Esse autor ainda afirma que o controle eficiente de plantas daninhas em consórcio talvez seja o principal desafio da pesquisa na atualidade, já que nem sempre a dose adequada de herbicidas para limitar o crescimento e desenvolvimento da planta consorciada é a mesma necessária para o adequado controle da flora invasora.

Há grande interesse na associação de métodos para controlar as plantas daninhas, incluindo o manejo cultural (Silva et al., 2009b). As capinas são muito trabalhosas e, por vezes, onerosas; contudo, de maneira geral são eficientes no controle de plantas daninhas. Já a aplicação de herbicida pode, além de causar danos ambientais, contribuir para a seleção de biótipos de plantas daninhas resistentes a esses insumos. O consórcio pode propiciar melhor aproveitamento dos recursos de produção e redução dos problemas de doenças e praga; além disso, pode controlar plantas daninhas, como visto por Araújo et al. (2012) na consorciação de milho com gliricidia.

Por outro lado, Duarte et al. (2007) consideram o controle manual, por meio da capina, pouco eficiente no controle da infestação, devido ao revolvimento do solo, resultando na transferência das sementes de plantas daninhas para a superfície do solo, necessitando de capinas adicionais ou de outras práticas em conjunto, como o consórcio.
O consórcio visando o controle de plantas daninhas no milho, tem sido feito especialmente com espécies da família Fabaceae (Alford et al., 2003; Kuchinda et al., 2003), embora outras também sejam utilizadas (Aladesanwa \& Adigun, 2008).

Sabe-se que comunidades infestantes, geralmente, variam em sua composição florística em razão do tipo e da intensidade de tratos culturais impostos. Entre os métodos mais utilizados, no reconhecimento florístico, principalmente em áreas agrícolas, está o estudo fitossociológico. Esse estudo em dado local e tempo permite fazer uma avaliação momentânea da composição da vegetação, obtendo dados de frequência, densidade, dominância; originando, assim, o índice de valor de importância das espécies ocorrentes naquela formação. Assim, o estudo fitossociológico é uma ferramenta que, se usada adequadamente, permite fazer várias inferências sobre a comunidade em questão (Erasmo et al., 2004).

Os objetivos deste trabalho foram efetuar o levantamento da comunidade de plantas daninhas no cultivo de milho em monocultivo e em consórcio, com diferentes Fabaceae, cultivado sob diferentes manejos, e verificar seus efeitos nas plantas daninhas e na altura e no peso do milho.

\section{MATERIAL E MÉTODOS}

O experimento foi realizado durante o período de primavera/verão de 2011/2012, no campo da Unidade de Apoio à Pesquisa e Extensão, coordenadas geográficas de $21^{\circ} 45^{\prime} 47^{\prime \prime}$ de latitude Sul e $41^{\circ} 17^{\prime} 12^{\prime}$ ' de longitude Oeste, da Universidade Estadual do Norte Fluminense Darcy Ribeiro, Campos dos Goytacazes - RJ. O solo é um Cambissolo Háplico, segundo o Sistema Brasileiro de Classificação do Solo (Embrapa, 2006), Francosiltoso com 10, 77,2 e 12,8\% de areia, silte e argila, respectivamente, e cujas características químicas da ca- 
mada de 0 - $20 \mathrm{~cm}$ de profundidade, por ocasião da instalação do experimento, e suas classificações, por Alvarez et al. (1999), são apresentadas na tabela 1.

Foi realizada análise de fertilidade do solo antes do plantio, utilizando-se uma amostra composta na profundidade de 0-20 cm, sendo suas determinações realizadas de acordo com Embrapa (1997) pelo laboratório de solos da Universidade Federal Rural do Rio de Janeiro, em Campos dos Goytacazes, Campos dos Goytacazes - RJ.

Os tratamentos avaliados foram: milho em monocultivo com adubação NPK na semeadura e com capina sobre palhada de milho em monocultivo com adubação NPK na semeadura e com capina (T1), milho em monocultivo sem adubação NPK na semeadura e com capina sobre palhada de milho em monocultivo sem adubação NPK na semeadura e com capina (T2), milho em monocultivo com adubação NPK na semeadura sem capina sobre palhada de milho em monocultivo com adubação NPK na semeadura sem capina (T3), consórcio milho + mucuna-preta com capina sobre palhada de consórcio milho + mucuna preta sem capina (T4), consórcio milho + crotalária sobre palhada de consórcio milho + crotalária sem capina (T5) e consórcio milho + feijão-de- porco sobre palhada de consórcio milho + feijão-de-porco sem capina (T6).

$\mathrm{O}$ experimento foi instalado em sistema de plantio direto, sem uso de herbicida, em que os tratamentos foram dispostos sobre palhada de tratamentos semelhantes. Para isso, roçaram-se as plantas do ciclo ante-

Tabela 1. Valores das características químicas de material do solo por ocasião da instalação do experimento (2011) em Campos dos Goytacazes (RJ) e suas classificações

\begin{tabular}{lcc}
\hline Característica & Valor encontrado & Classificação \\
\hline $\mathrm{pH}$ & 5,90 & Bom \\
$\mathrm{P} *\left(\mathrm{mg} / \mathrm{dm}^{3}\right)$ & 4,00 & Muito baixo \\
$\mathrm{K} *\left(\mathrm{mg} / \mathrm{dm}^{3}\right)$ & 69,00 & - \\
$\mathrm{Ca}\left(\mathrm{cmol}_{\mathrm{c}} / \mathrm{dm}^{3}\right)$ & 6,30 & Muito bom \\
$\mathrm{Mg}\left(\mathrm{cmol}_{\mathrm{c}} / \mathrm{dm}^{3}\right)$ & 3,90 & Muito bom \\
$\mathrm{Al}\left(\mathrm{cmol}_{\mathrm{c}} / \mathrm{dm}^{3}\right)$ & 0,00 & Muito baixo \\
$\mathrm{H}+\mathrm{Al}\left(\mathrm{cmol}_{\mathrm{c}} / \mathrm{dm}^{3}\right)$ & 4,30 & Médio \\
$\mathrm{Na}\left(\mathrm{cmol}_{\mathrm{c}} / \mathrm{dm}^{3}\right)$ & 0,37 & - \\
$\mathrm{S} . \mathrm{B} .\left(\mathrm{cmol}_{\mathrm{c}} / \mathrm{dm}^{3}\right)$ & 10,70 & Muito bom \\
$\mathrm{T}\left(\mathrm{cmol} / \mathrm{dm}^{3}\right)$ & 15,00 & Baixo \\
$\mathrm{t}\left(\mathrm{cmol} / \mathrm{dm}^{3}\right)$ & 10,70 & Muito bom \\
$\mathrm{MO}\left(\mathrm{g} / \mathrm{dm}^{3}\right)$ & 30,50 & Médio \\
$\mathrm{C}(\%)$ & 1,77 & Médio \\
$\mathrm{m}(\%)$ & 0,00 & - \\
$\mathrm{V}(\%)$ & 71,00 & Bom \\
$\mathrm{Fe}\left(\mathrm{mg} / \mathrm{dm}^{3}\right)$ & 61,20 & Muito bom \\
$\mathrm{Cu}\left(\mathrm{mg} / \mathrm{dm}^{3}\right)$ & 3,10 & Muito bom \\
$\mathrm{Zn}\left(\mathrm{mg} / \mathrm{dm}^{3}\right)$ & 4,00 & Muito bom \\
$\mathrm{Mn}\left(\mathrm{mg} / \mathrm{dm}^{3}\right)$ & 22,20 & Muito bom \\
$* \mathrm{Extrator} \mathrm{Carolina}$ & &
\end{tabular}

* Extrator Carolina do Norte rior, as quais já se apresentavam extremamente secas, procurando deixá-las nas unidades experimentais de origem. Logo após, foram preparados os sulcos, com auxílio de sulcador e trator, para a realização da semeadura dos tratamentos.

Utilizou-se delineamento em blocos casualizados, com quatro repetições.

Cada unidade experimental (U.E.) do monocultivo de milho foi constituída de cinco linhas de cinco metros, com um metro de espaçamento. A U.E. de cada consórcio foi constituída por cinco fileiras de milho intercaladas por quatro fileiras de fabaceae com cinco metros de comprimento, espaçadas de um metro, tendo como área útil três linhas centrais de milho, descartando-se cinquenta centímetros das suas extremidades.

O cultivar de milho utilizado foi o híbrido interpopulacional UENF 506/11.

Fez-se a análise de solo para determinar a adubação, recomendada para os solos do Estado do Rio de Janeiro por De-Polli et al. (1988). As doses de NPK aplicadas foram de 80-80-20 kg.ha-1, utilizando-se como fontes sulfato de amônio, superfosfato simples e cloreto de potássio, respectivamente. O superfosfato simples e o cloreto de potássio foram aplicados em suas totalidades, juntamente com $2 / 3$ da dose do sulfato de amônio, imediatamente antes da semeadura. $\mathrm{O}$ restante do $\mathrm{N}$ foi aplicado na adubação de cobertura, que foi feita apenas no milho em monocultivo dos tratamentos T1 e T3, nos dois ciclos de cultivo.

A adubação nitrogenada de cobertura foi realizada aos 17 dias após emergência (d.a.e.) nos tratamentos T1 e T3. Nessa época as plantas de milho apresentavam-se com seis a oito folhas. No segundo ciclo de cultivo, visto que nos demais tratamentos as plantas de milho estavam muito pequenas, decidiu-se por realizar adubação de cobertura com a mesma dosagem dos tratamentos T1 e T3, também nesses tratamentos, aos 29 d.a.e.

Na semeadura do milho foram utilizadas 10 sementes por metro linear, enquanto da crotalária 15 sementes e do feijão-de-porco e na da mucuna-preta quatro sementes por metro linear.

Foi realizada a inoculação usando inoculantes com as estirpes Bradyrhizobium sp. (BR 2003), para crotalária; as Bradyrhizobium sp. (BR 2003) e B. elkanii (BR 2811), para o feijão-de-porco, e B. elkanii (BR 2811), para a mucuna-preta, fornecidos pela Embrapa Agrobiologia, utilizando a metodologia sugerida por essa empresa.

As plantas de milho foram desbastadas quando atingiram entre seis e oito folhas, deixando uma população de 50.000 plantas/ha.

No segundo ciclo, durante o cultivo foram realizadas três capinas aos 15, 30 e 55 d.a.e., em todos os trata-

Rev. Ceres, Viçosa, v. 61, n.5, p. 643-651, set/out, 2014 
mentos, com exceção do tratamento de monocultivo de milho sem capina (T2).

Todos os tratamentos foram submetidos à irrigação por aspersão de maneira suficiente e adequada às culturas.

Aos 44 d.a.e mediu-se, com auxílio de fita métrica, a altura de três plantas de milho escolhidas aleatoriamente em cada unidade experimental; fez-se então a média para a obtenção da altura média do milho. Para a obtenção do peso da matéria seca do milho foram cortadas, rente ao solo, três plantas de milho, de cada unidade experimental, que foram armazenadas em sacos de papel e levadas para secagem em estufa de circulação forçada de ar à temperatura de $75^{\circ} \mathrm{C}$, por 72 horas, para determinação de sua matéria seca, após pesagem.

Também aos 44 d.a.e., foram medidas as alturas das plantas daninhas, escolhendo-se três pontos, aleatórios, em cada unidade experimental, e mediu-se a altura da maior planta daninha nesse ponto.

Foram coletadas amostras das plantas infestantes em todos os tratamentos, aos 45 d.a.e., laçando-se um quadro de 0,5 x 0,5 m, aleatoriamente, em cada uma das unidades experimentais. Todas as plantas abrangidas pelo quadro foram coletadas, cortando-as rente ao solo. Foram coletadas duas amostras em cada unidade experimental, as quais foram armazenadas em sacos plásticos e levadas ao laboratório, onde as plantas foram identificadas com auxílio de literatura especializada (Lorenzi \& Matos (2002), Lorenzi (2006) e Lorenzi (2008)) e depois quantificadas. Após a identificação, as plantas foram armazenadas em sacos de papel devidamente identificados e levadas para secagem em estufa de circulação forçada de ar à temperatura de $75^{\circ} \mathrm{C}$ por 72 horas, para determinação de sua matéria seca.

Avaliaram-se a densidade relativa (Dr), a frequência absoluta $(\mathrm{Fa})$, a frequência relativa $(\mathrm{Fr})$, a dominância relativa (DoR) e o índice de valor de importância (IVI), de acordo com Curtis \& Mclnstosh (1950) e MüellerDombois \& Ellenberg (1974).

Foi realizada a análise de variância dos dados, e para as variáveis em que ocorreu efeito significativo $(\mathrm{P}<0,05)$ avaliou-se o efeito de contrastes ortogonais (Tabela 2).

As análises foram realizadas com auxílio do aplicativo SAEG - Sistemas para Análises Estatísticas, versão 9.0 (Ribeiro Júnior, 2007).

\section{RESULTADOS E DISCUSSÃO}

O levantamento fitossociológico permitiu a identificação de 16 espécies de plantas daninhas infestando a cultura do milho, em monocultivo e em consórcio, distribuídas em oito famílias. As famílias mais representativas, no que se refere ao número de espécies, foram a Asteraceae e a Poaceae, com quatro espécies cada uma, seguidas pela Euphorbiaceae, com três espécies. As demais apresentaram apenas uma espécie cada. Quanto ao tipo de folha, apenas as famílias Cyperaceae e Poaceae enquadram-se no tipo folhas estreitas (monocotiledôneas), enquanto as demais são de espécies com folhas largas (dicotiledôneas) (Tabela 3).

Em média, foi observada no monocultivo maior diversidade de plantas daninhas com 10 espécies, sendo o camalote (Rottboelia exaltata), o falso massambará (Sorghum arundinaceum) e o apaga-fogo (Alternanthera tenella colla) as espécies em destaque. No cultivo em consórcio foram identificadas oito espécies infestantes (Figuras 1 e 2). Tal resultado corrobora com Rosa et al. (2011), que observaram menores valores de incidência de plantas invasora nos tratamentos de milho em consórcio com três espécies de fabaceaes, quando comparadas ao milho em monocultivo.

Observando o IVI de cada espécie de planta daninha, de acordo com os tratamentos do milho em monocultivo, pode-se verificar que o camalote ( $R$. exaltata) apresen-

Tabela 2. Contrastes ortogonais utilizados para a análise estatística dos dados

\begin{tabular}{|c|c|}
\hline Contraste & Comparação \\
\hline $\begin{array}{l}\mathrm{C} 1-\text { Milho em monocultivo }(\mathrm{T} 1+\mathrm{T} 2+\mathrm{T} 3) \text { versus milho em } \\
\text { consórcio }(\mathrm{T} 4+\mathrm{T} 5+\mathrm{T} 6)\end{array}$ & Compara o monocultivo com o consórcio (sistema de cultivo) \\
\hline $\begin{array}{l}\mathrm{C} 2 \text { - Milho em monocultivo com capina }(\mathrm{T} 1+\mathrm{T} 2) \text { versus } \\
\text { milho em monocultivo sem capina }(\mathrm{T} 3)\end{array}$ & Compara o efeito da capina no monocultivo \\
\hline $\begin{array}{l}\text { C3 - Milho em monocultivo com capina com adubação comple- } \\
\text { ta (T1) versus milho em monocultivo com capina sem adubação } \\
\text { completa (T2) }\end{array}$ & Compara o efeito da adubação no monocultivo \\
\hline $\begin{array}{l}\text { C4 - Milho em consórcio com mucuna preta (T4) versus milho } \\
\text { em consórcio com crotalária e milho em consórcio com feijão de } \\
\text { porco (T5+T6) }\end{array}$ & $\begin{array}{l}\text { Compara o efeito da mucuna preta com a média das outras } \\
\text { fabaceaes, consorciadas com o milho }\end{array}$ \\
\hline $\begin{array}{l}\text { C5 - Milho em consórcio com crotalária (T5) versus milho em } \\
\text { consórcio com feijão de porco (T6) }\end{array}$ & $\begin{array}{l}\text { Compara o efeito da crotalária com o do feijão de porco, consor- } \\
\text { ciados com o milho }\end{array}$ \\
\hline
\end{tabular}


tou IVIs elevados, especialmente nos tratamentos com adubação com NPK na semeadura, enquanto no monocultivo sem NPK na semeadura os valores de IVI foram em média cinco vezes menores (Tabela 4).

Quando se compara os IVIs das espécies infestantes dos tratamentos capinados e do não capinado, observase que o falso massambará ( $S$. arundinaceum) apresentou IVI 10 vezes maior no tratamento que não obteve esse manejo (Tabela 4).

Já o apaga-fogo (Alternanthera. tenellacolla) obteve alto IVI no tratamento 2 , no qual não foi realizada a adubação NPK na semeadura (Tabela 4). Com isso, podese afirmar que a adubação NPK na semeadura auxiliou no controle dessa espécie de planta daninha.

O camalote ( $R$. exaltata) foi bastante representativo no tratamento do milho em consórcio com a mucunapreta, apresentando IVI de 142,11. Devido à altura desta espécie, isso se relaciona com a maior altura das plantas daninhas (ALPD) nesse tratamento, comparando-o com os demais consórcios (Tabela 5).

O falso massambará ( $S$. arundinaceum) obteve IVI de 160,11 no tratamento do milho com a crotalária, sendo esse IVI cinco vezes maior que a média dos demais tratamentos. Isso aumentou a possibilidade de maior peso da matéria seca de plantas daninhas de folhas estreitas nesse tratamento, comparado aos demais.

A Tabela 5 mostra as estimativas dos contrastes de peso da matéria seca das plantas daninhas de folhas estreitas, peso da matéria seca das plantas daninhas de folhas largas, altura das plantas daninhas, altura do milho e peso da matéria seca do milho.
Apesar de apenas duas famílias (Cyperaceae e Poaceae) se enquadrarem no tipo folhas estreitas e de o número de espécies de folhas largas (11) ser maior que o de folhas estreitas (5) (Tabela 3), na análise das estimativas dos contrastes apenas o peso da matéria seca das espécies de plantas daninhas de folhas estreitas apresentou significância, enquanto o da matéria seca das plantas daninhas de folhas largas não apresentou efeitos significativos dos contrastes (Tabela 5).

Ocorreu efeito do sistema de cultivo, observado pelo contraste $\mathrm{C} 1$, sobre o peso da matéria seca das plantas daninhas de folhas estreitas, a altura das plantas daninhas e sobre a altura e o peso da matéria seca do milho (Tabela 5). Nessas três variáveis, pode-se observar que, apesar de as plantas daninhas serem mais altas, no monocultivo de milho esse sistema também apresentou maior altura do milho e maior peso de matéria seca que as plantas de milho em consórcio. Já Silva et al. (2009a) observaram que a produtividade de fitomassa superou à dos monocultivos dessas gramíneas, em consorciações de sorgo e milho com outras espécies.

A semente de milho possui grande quantidade de reserva e, além disto, a planta, em condições favoráveis de clima e solo, geralmente possui maior volume do sistema radicular em comparação às plantas daninhas, propiciando maior desenvolvimento do milho, fazendo com que, consequentemente, ocorra rápido fechamento entre linha, diminuindo a incidência de luz sobre as demais plantas, acarretando em menor taxa de crescimento delas (Gimenes et al., 2008). O fechamento entre linha pode ser aumentado quando o milho está em consórcio

Tabela 3. Plantas daninhas identificadas pela família, pela espécie e pelo nome comum e seu tipo de folha, considerando todos os tratamentos de milho em monocultivo e em consórcio

\begin{tabular}{lccc}
\hline Família & Espécie & Nome comum & Tipo de folha \\
\hline Amaranthaceae & Alternanthera tenella colla & Apaga-fogo & Larga \\
\hline Asteraceae & Emilia fosbergii & Falsa-Serralha & Larga \\
& Emilia sonchifolia & Serralha & Larga \\
& Galinsoga parviflora & Botão-de-ouro & Larga \\
\hline Cabombaceae & Clinsoga quadriradiata & Botão-de-ouro & Larga \\
\hline Cyperaceae & Cyperus ferax & Mussambê & Larga \\
\hline \multirow{2}{*}{ Euphorbiaceae } & Croton lobatus & Tiriricão & Estreita \\
\hline Malvaceae & Cuphorbia heterophylla & Erva-de-Santa-Luzia & Larga \\
\hline & Ricinus communis $L$. & Mamona & Larga \\
Poaceae & Wissadula subpeltata & Malva-estrela & Larga \\
\hline Portulacaceae & Cynodon dactylon & Grama-seda & Estreita \\
\hline & Panicum numidianum & Capim-angola & Estreita \\
\hline & Rottboelia exaltata & Camalote & Estreita \\
\hline
\end{tabular}


com outras culturas, possivelmente por isso a altura das plantas daninhas do milho em monocultivo foi superior à do milho em consórcio.

As espécies de maiores IVIs no monocultivo do milho foram, em geral, apaga- fogo (A. tenella colla) e camolote ( $R$. exaltata), sendo essas espécies de arquitetura ereta, o que possivelmente também influenciou na altura das plantas daninhas presentes nesse sistema de cultivo.

A capina no monocultivo (C2), assim como ocorreu com o sistema de cultivo (C1), apresentou efeito significativo sobre a altura e o peso da matéria seca do milho e das plantas daninhas, apesar da altura das plantas daninhas e o peso da matéria seca das plantas daninhas de folhas estreitas também serem maiores nos tratamentos capinados. Esse aumento de altura e de peso da matéria seca do milho ocorreu, possivelmente, devido à diminuição de competição entre elas, causada pela capina. Pires et al. (2005) também verificaram efeito positivo sobre o aumento do peso da matéria seca da parte aérea de soja quando submetida à capina das plantas daninhas. Por outro lado, Araújo et al. (2012), trabalhando com milho, verificaram que a massa seca da parte aérea das plantas daninhas nas parcelas não capinadas não diferiu da observada nas parcelas consorciadas, porém ambas foram superiores à massa seca da parte aérea das plantas daninhas nas parcelas que receberam duas capinas. Devese ressaltar que a $R$. exaltata, planta infestante com maior
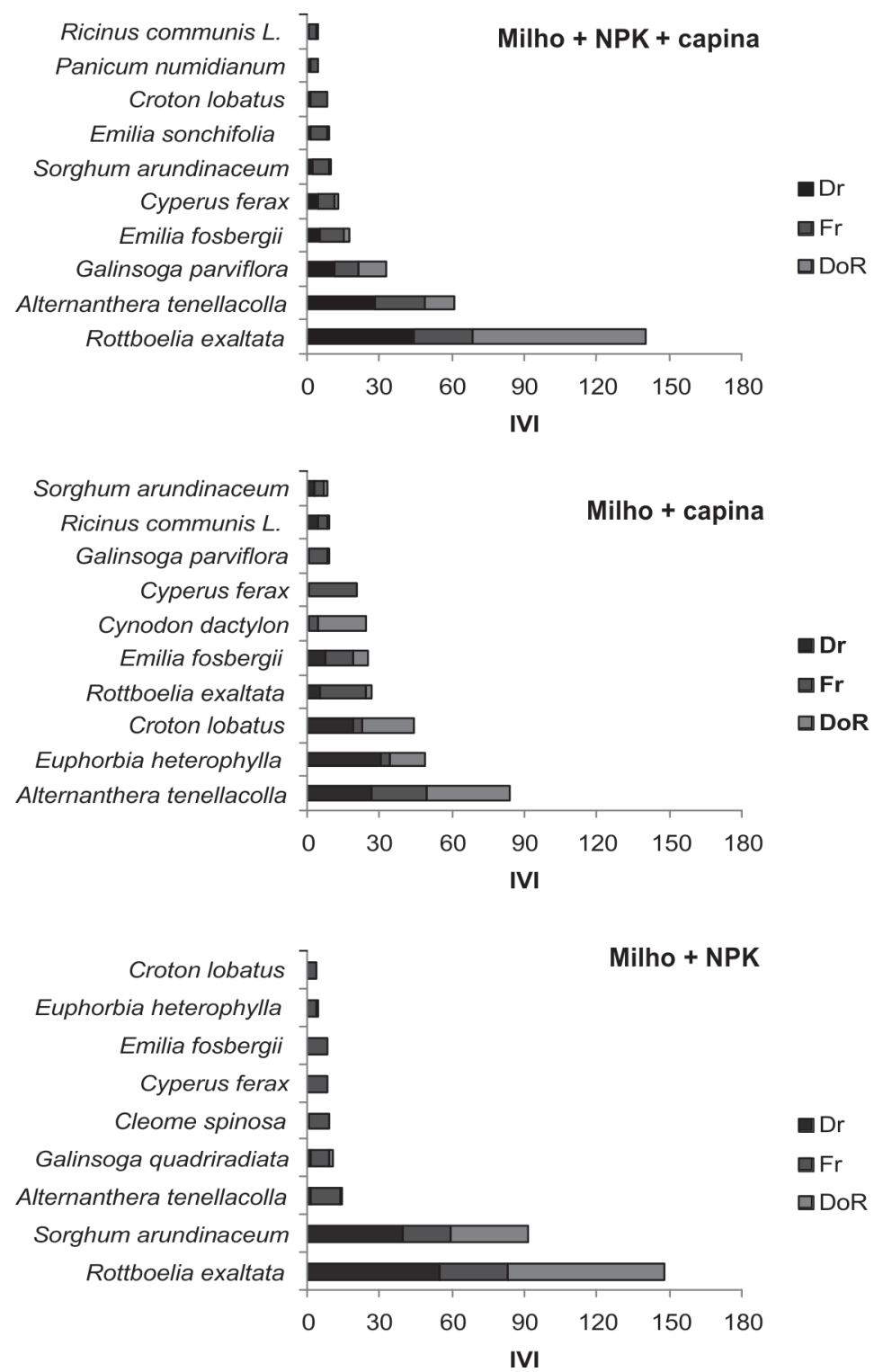

Figura 1. Índice de Valor de Importância (IVI) das espécies infestantes, considerando o milho em monocultivo, com NPK na semeadura e com capina (T1), milho em monocultivo sem NPK na semeadura com capina (T2) e milho em monocultivo com NPK na semeadura sem capina (T3). $\mathrm{Dr}=$ densidade relativa $\mathrm{Fr}=$ frequência relativa e $\mathrm{DoR}=$ dominância relativa. 
IVI nos tratamentos do milho em monocultivo capinado, é uma planta agressiva, altamente prolífera, de desenvolvimento rápido e capaz de produzir estruturas de propagação vegetativa além das sementes (Carvalho et al., 2005).

No intervalo entre a segunda capina e a avaliação, ou seja de 15 dias, ocorreu o crescimento das plantas daninhas de folhas estreitas, enquanto as de folha larga não recuperaram, porém a capina também influenciou de forma positva na ALM e no PMSM.

A adubação apresentou efeito significativo (C3) sobre as mesmas variáveis que a capina (C2), com exceção da ALM (Tabela 5). O peso da matéria seca das plantas daninhas de folhas estreitas (PMSPDE) aumentou com a adubação (Tabela 5), possivelmente por ter aumentado a disponibilidade de NPK no solo também favoreceu as plantas daninhas no acúmulo de matéria seca. Entretanto, os tratamentos em monocultivo que tiveram adubação com NPK apresentaram plantas daninhas menores que o tratamento que não recebeu essa adubação. A adubação com NPK no milho em monocultivo capinado favoreceu o aumento da população de camalote $(R$. exaltata) e apaga-fogo (A. tenella colla), resultando, em ambos os casos, em IVI cinco vezes maior que o milho capinado quando não recebeu a adubação com NPK (Tabela 4). O aumento da população do camalote $(R$. exaltata) certamente resultou no aumento do PMSPDE. O contraste demonstra que, em média, as plantas dani-
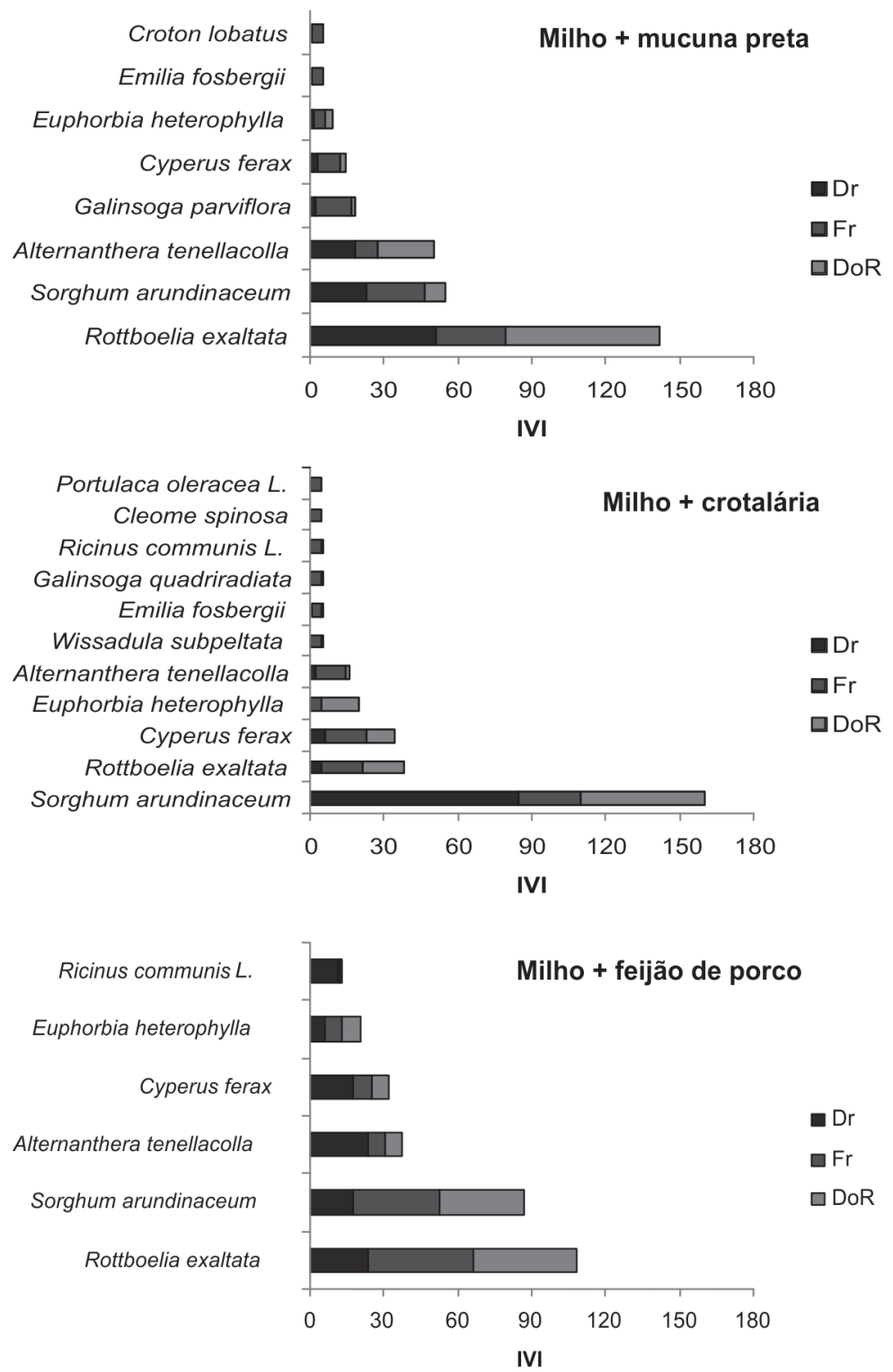

Figura 2. Índice de Valor de Importância (IVI) das espécies infestantes, considerando o consórcio milho + mucuna-preta (T4), consórcio milho + crotalária (T5) e consórcio milho + feijão-de-porco (T6). Dr = densidade relativa, Fr = frequência relativa e DoR $=$ dominância relativa. 
nhas no tratamento não adubado com NPK apresentaram-se aproximadamente $63 \mathrm{~cm}$ mais altas (Tabela 5).

O peso da matéria seca do milho foi maior nos tratamentos adubados com NPK na semeadura, demonstrando o efeito positivo da adubação mineral para a cultura do milho em monocultivo. Silva et al. (2009a) também verificaram as maiores produções de massa seca do milho quando foi realizada a adubação nitrogenada. No presente trabalho, além do nitrogênio, também foram fornecidos o $\mathrm{P}$ e o $\mathrm{K}$ no tratamento com adubação completa. Vale ressaltar que o aumento da população do camalote (R. exaltata), devido à adubação NPK (Ta- bela 4), não foi suficiente para diminuir o crescimento do milho, pois certamente o aumento da disponibilidade de NPK no início do ciclo da cultura do milho resultou em plantas mais vigorosas; ou seja, com maior peso da matéria seca (Tabela 5).

Quando se analisa a diferença entre o consórcio com a mucuna-preta e as demais fabaceas (C4) pode-se observar que não houve efeito significativo em nenhuma das variáveis analisadas (Tabela 5).

O mesmo ocorreu no contraste que confronta o consórcio do milho com a crotalária, e o consórcio do milho com o feijão-de-porco não apresentou efeito signi-

Tabela 4. Valores de IVI no milho em monocultivo com adubação mineral na semeadura (T1), milho em monocultivo sem adubação mineral na semeadura (T2), milho em monocultivo com adubação mineral na semeadura sem capina (T3), milho + mucuna preta (T4), milho + crotalária (T5) e milho + feijão-de-porco (T6)

\begin{tabular}{|c|c|c|c|c|c|c|c|}
\hline \multirow{5}{*}{ Família } & \multirow{5}{*}{ Espécie } & \multicolumn{6}{|c|}{ Tratamentos } \\
\hline & & T1 & $\mathbf{T} 2$ & T3 & $\mathbf{T 4}$ & T5 & T6 \\
\hline & & \multicolumn{3}{|c|}{ Monocultivos de milho } & \multicolumn{3}{|c|}{ Consórcios } \\
\hline & & \multicolumn{2}{|c|}{ Capina } & \multirow{2}{*}{$\begin{array}{c}\text { Sem capina } \\
\text { NPK na } \\
\text { semeadura }\end{array}$} & \multicolumn{3}{|c|}{ Capina } \\
\hline & & $\begin{array}{c}\text { NPK na } \\
\text { semeadura }\end{array}$ & $\begin{array}{c}\text { Sem NPK na } \\
\text { semeadura }\end{array}$ & & $\begin{array}{c}\text { Mucuna- } \\
\text { preta }\end{array}$ & Crotalária & $\begin{array}{l}\text { Feijão-de- } \\
\text { porco }\end{array}$ \\
\hline Amaranthaceae & A. tenella colla & 60,87 & 83,74 & 14,63 & 50,07 & 16,29 & 37,75 \\
\hline \multirow[t]{4}{*}{ Asteraceae } & E. fosbergii & 17,18 & 24,86 & 8,41 & 5,65 & 5,60 & - \\
\hline & E. sonchifolia & 8,89 & - & - & - & - & - \\
\hline & G. parviflora & 32,79 & 8,91 & - & 18,20 & - & - \\
\hline & G. quadriradiata & - & - & 10,62 & - & 5,34 & - \\
\hline Cabombaceae & C. spinosa & - & - & 9,46 & - & 4,92 & - \\
\hline Cyperaceae & C. ferax & 12,87 & 20,87 & 8,71 & 14,11 & 34,28 & 32,27 \\
\hline \multirow[t]{3}{*}{ Euphorbiaceae } & C. lobatus & 8,36 & 44,54 & 4,19 & 5,50 & - & - \\
\hline & E. heterophylla & - & 48,70 & 4,42 & 9,23 & 19,63 & 20,81 \\
\hline & R. communis $L$. & 4,42 & 8,86 & - & - & 5,09 & 13,29 \\
\hline Malvaceae & W. subpeltata & - & - & - & - & 5,68 & - \\
\hline \multirow[t]{4}{*}{ Poaceae } & C. dactylon & - & 24,61 & - & - & - & - \\
\hline & P. numidianum & 4,92 & - & - & - & - & - \\
\hline & R. exaltata & 139,96 & 26,34 & 144,98 & 142,11 & 38,39 & 108,62 \\
\hline & S. arundinaceum & 9,75 & 8,57 & 91,57 & 55,13 & 160,11 & 87,25 \\
\hline Portulacaceae & P. oleracea & - & - & - & - & 4,68 & - \\
\hline
\end{tabular}

Tabela 5. Estimativas de contrastes ortogonais das médias por parcela para peso da matéria seca das plantas daninhas de folhas estreitas (PMSPDE), peso da matéria seca das plantas daninhas de folhas largas (PMSPDL), altura das plantas daninhas (ALPD), altura do milho (ALM) e peso da matéria seca do milho (PMSM), seguidas das maiores médias, em caso de significância

\begin{tabular}{lccccc}
\hline Contrastes & $\begin{array}{c}\text { PMSPDE } \\
\left(\mathbf{m g ~ m}^{-2}\right)\end{array}$ & $\begin{array}{c}\text { PMSPDL } \\
\left(\mathbf{m g ~ m}^{-2}\right)\end{array}$ & $\begin{array}{c}\text { ALPD } \\
(\mathbf{c m})\end{array}$ & $\begin{array}{c}\text { ALM } \\
(\mathbf{c m})\end{array}$ & $\begin{array}{c}\text { PMSM } \\
(\mathbf{g})\end{array}$ \\
\hline 1 & $41,60^{* *}$ & 6,28 & $30,75^{* *}$ & $41,53^{* *}$ & $26,95^{* *}$ \\
2 & $58,08^{* *}$ & $-5,27$ & $45,46^{* *}$ & $75,75^{* *}$ & $19,13^{* *}$ \\
3 & $19,89^{*}$ & 9,20 & $-63,09^{* *}$ & $11,17^{\text {n.s. }}$ & $25,23^{* *}$ \\
4 & $4,40^{\text {n.s. }}$ & 2,86 & $5,04^{\text {n.s. }}$ & $-8,58^{\text {n.s. }}$ & $-0,46^{\text {n.s. }}$ \\
5 & $4,55^{\text {n.s. }}$ & $-0,01$ & $12,75^{\text {n.s. }}$ & $6,33^{\text {n.s. }}$ & $7,45^{\text {n.s. }}$ \\
\hline C.V. $(\%)$ & 105,22 & 102,54 & 60,43 & 20,17 & 40,50 \\
\hline
\end{tabular}

* Significativo a $5 \%$ de probabilidade.** Significativo a $1 \%$ de probabilidade.

${ }^{\text {ns }}$ Não significativo.

Rev. Ceres, Viçosa, v. 61, n.5, p. 643-651, set/out, 2014 
ficativo $(\mathrm{P}<0,05)$, mostrando semelhança entre essas duas espécies de fabaceae, quando se refere às variáveis analisadas. Porém, quando se observa a quantidade de espécies de plantas daninhas nesses dois tratamentos, verifica-se menor número no tratamento do milho em consórcio milho com feijão-de-porco (Figura 2), podendo isso ser justificado por seu efeito alelopático sobre algumas plantas invasoras (Carvalho et al., 2002).

\section{CONCLUSÕES}

O monocultivo apresenta maior diversidade de plantas daninhas em relação ao consórcio e resulta em maior peso da matéria seca de plantas daninhas de folhas estreitas e plantas daninhas mais altas.

O monocultivo e a capina apresentam plantas de milho com maior altura e peso de matéria seca.

$\mathrm{O}$ peso da matéria seca das plantas daninhas de folhas estreitas aumenta com a adubação NPK e com a capina.

A adubação com NPK resulta em plantas daninhas menores.

A capina eleva a altura das plantas daninhas e o peso da matéria seca das plantas daninhas de folhas estreitas.

A capina aumenta o IVI do falso massambará ( $S$. arundinaceum).

A adubação com NPK diminui o IVI do apaga-fogo (A. tenella colla).

O consórcio com a mucuna-preta aumenta o IVI do camalote ( $R$. exaltata), já com a crotalária favorece o falso massambará (S. arundinaceum).

\section{AGRADECIMENTOS}

À FAPERJ, pelo suporte financeiro para a implantação dos experimentos de campo e às análises laboratoriais.

\section{REFERÊNCIAS}

Aladesanwa RD \& Adigun AW (2008) Evaluation of sweet potato (Ipomoea batatas) live mulch at different spacings for weed suppression and yield response of maize (Zea mays L.) in Southwestern Nigeria. Crop Protection, 27:968-975.

Alford CM, Krall JM \& Miller SD (2003) Intercropping irrigated corn with annual legumes for fall forage in the High Plains. Agronomy Journal, 95:520-525.

Alvarez V VH, Novais RF, Barros NF, Cantarutti RB \& Lopes AS (1999) Interpretação dos resultados das análises de solos. In: Ribeiro AC, Guimarães PTG \& Alvarez V VH (Eds.) Recomendações para uso de corretivos e fertilizantes em Minas Gerais. Viçosa, CFSEMG. p.25-32. 5 Aproximação.

Araújo Júnior BB, Silva PSL, Oliveira OF \& Espinola Sobrinho J (2012) Controle de plantas daninhas na cultura do milho com gliricídia em consorciação. Planta Daninha, 30:767-774.
Carvalho GJ, Fontanetti A \& Cançado CT (2002) Potencial alelopático do feijão de porco (Canavalia ensiformes) e da mucuna preta (Stilozobium aterrimum) no controle da tiririca (Cyperus rotandus). Ciência e Agrotecnologia, 26:647-651.

Carvalho SJP, Moreira MS, Nicolai M, López-Ovejero RF, Christoffoleti PJ \& Medeiros D (2005) Crescimento e desenvolvimento da planta daninha capim-camalote (Rottboelia exaltata). Bragantia, 64:591-600.

Curtis JT \& McIntosh RP (1950) The Interelations of certain analytic and synthetic phytosociological characters. Ecology, 31:434-455.

Dan HA, Oliveira Júnior RS, Constantin J, Dan LGM, Braz GBP, Balbinot E, Sousa FG \& Reis RHP (2012) Controle de plantas daninhas em sistemas de cultivo consorciados. Revista Brasileira de Herbicidas, 11:108-118.

De-Polli H, Almeida DL, Santos GA, Cunha LH, Freire LR, Amaral Sobrinho NMB, Pereira NNC, Eira PA, Bloise RM \& Salek RC (1988) Manual de adubação para o Estado do Rio de Janeiro. $2^{\mathrm{a}}$ ed. Rio de Janeiro, Editora Universidade Rural. 179p.

Duarte AP, Silva AC \& Deuber R (2007) Plantas infestantes em lavouras de milho safrinha, sob diferentes manejos, no médio Paranapanema. Planta Daninha, 25:285-291.

Embrapa - Empresa Brasileira de Pesquisa Agropecuária (1997) Manual de métodos de análise de solo. $2^{\mathrm{a}}$ ed. Rio de Janeiro, CNPS - Ministério da Agricultura e do Abastecimento. 212p.

Embrapa - Empresa Brasileira de Pesquisa Agropecuária (2006) Sistema brasileiro de classificação de solos. Rio de Janeiro, Embrapa Solos. 306p.

Erasmo EAL, Pinheiro LLA \& Costa NV (2004) Levantamento fitossociológico das comunidades de plantas infestantes em áreas de produção de arroz irrigado cultivado sob diferentes sistemas de manejo. Planta Daninha, 22:195-201.

Gimenes MJ, Victoria Filho R, Prado EP, Dal Pogetto MHFA \& Christovam RS (2008) Interferência de espécies forrageiras em consórcio com a cultura do milho. Revista da FZVA, 15:61-76.

Kuchinda, NC, Kureh I, Tarfa BD, Shinggu C \& Omolehin R (2003) Onfarm evaluation of improved maize varieties intercropped with some legumes in the control of Striga in the Northern Guinea savanna of Nigeria. Crop Protection, 22:533-538.

Lorenzi H \& Matos FJA (2002) Plantas Medicinais do Brasil: nativas e exóticas. Nova Odessa, Instituto Plantarum. 512p.

Lorenzi H (2006) Manual de identificação e controle de plantas daninhas: plantio direto e convencional. $6^{\mathrm{a}}$ ed. Nova Odessa, Instituto Plantarum. 672p.

Lorenzi H (2008) Plantas Daninhas do Brasil: terrestres, aquáticas, parasitas e tóxicas. $4^{\mathrm{a}}$ ed. Nova Odessa, Instituto Plantarum. 640p.

Müeller-Dombois D \& Ellemberg H (1974) Aims and methods of vegetation ecology. New York, John Wiley. 347p.

Pires FR, Menezes CCE, Procópio SO, Barroso ALL, Menezes JFS, Leonardo LM, Sousa JPG, Vieira AB \& Zanatta JF (2005) Potencial competitivo de cultivares de soja em relação às plantas daninhas. Planta Daninha, 23:575-581.

Ribeiro Júnior JI (2007) Análises estatísticas no SAEG. Viçosa, UFV. $301 p$.

Rosa DM, Nóbrega LHP, Mauli MM \& Lima GP (2011) Comportamento da comunidade invasora na cultura do milho consorciado com leguminosas. Varia Scientia Agrárias, 2:99-106.

Silva MAG, Porto SMA, Mannigel AR, Muniz AS, Mata JDV \& Numoto AY (2009a) Manejo da adubação nitrogenada e influência no crescimento da aveia preta e na produtividade do milho em plantio direto. Acta Scientiarum Agronomy, 31:275-281.

Silva PCG, Foloni JSS, Fabris LB \& Tiritan CS (2009b) Fitomassa e relação $\mathrm{C} / \mathrm{N}$ em consórcios de sorgo e milho com espécies de cobertura. Pesquisa Agropecuária Brasileira, 44:1504-1512.

Rev. Ceres, Viçosa, v. 61, n.5, p. 643-651, set/out, 2014 